\title{
Cerebral Edema
}

National Cancer Institute

\section{Source}

National Cancer Institute. Cerebral Edema. NCI Thesaurus. Code C4909.

Swelling due to an excessive accumulation of fluid in the brain. 